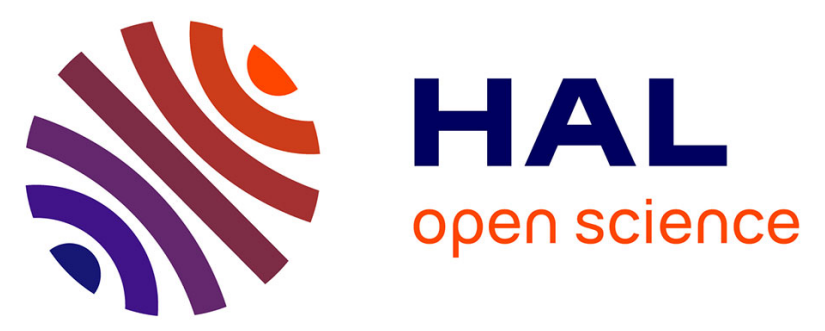

\title{
Two-photon absorption and fluorescence in nanoscale multipolar chromophores: effect of dimensionality and charge-symmetry
}

Laurent Porrès, Claudine Katan, Olivier Mongin, Thomas Pons, Jerome Mertz, Mireille Blanchard-Desce

\section{To cite this version:}

Laurent Porrès, Claudine Katan, Olivier Mongin, Thomas Pons, Jerome Mertz, et al.. Two-photon absorption and fluorescence in nanoscale multipolar chromophores: effect of dimensionality and chargesymmetry. Journal of Molecular Structure, 2004, From Molecules to Molecular Biological Systems and Molecular Materials: The role of Molecular Interactions and Molecular Recognition, 704 (1-3), pp.1724. 10.1016/j.molstruc.2003.12.036 . hal-01416768

\section{HAL Id: hal-01416768 \\ https://hal-univ-rennes1.archives-ouvertes.fr/hal-01416768}

Submitted on 14 Dec 2016

HAL is a multi-disciplinary open access archive for the deposit and dissemination of scientific research documents, whether they are published or not. The documents may come from teaching and research institutions in France or abroad, or from public or private research centers.
L'archive ouverte pluridisciplinaire HAL, est destinée au dépôt et à la diffusion de documents scientifiques de niveau recherche, publiés ou non, émanant des établissements d'enseignement et de recherche français ou étrangers, des laboratoires publics ou privés. 
Journal of Molecular Structure, Volume 704, Issues 1-3, 18 October 2004, Pages 17-24, http://dx.doi.org/10.1016/j.molstruc.2003.12.036

Two-Photon Absorption and Fluorescence in Nanoscale Multipolar Chromophores: Effect of dimensionality and charge-symmetry.

Laurent Porrès, ${ }^{\mathrm{a}}$ Claudine Katan, ${ }^{\mathrm{a}}$ Olivier Mongin, ${ }^{\mathrm{a}}$ Thomas Pons, ${ }^{\mathrm{b}}$ Jerome Mertz ${ }^{\mathrm{b}, \#}$ and Mireille Blanchard-Desce ${ }^{\mathrm{a}, *}$

${ }^{a}$ Synthèse et ElectroSynthèse Organiques (CNRS, UMR 6510), Université de Rennes 1, Institut de Chimie, Campus Scientifique de Beaulieu, Bât 10A, F-35042 Rennes Cedex,

\title{
France
}

${ }^{b}$ Neurophysiologie et Nouvelles Microscopies (INSERM EPI 00-02, CNRS FRE 2500), Ecole Supérieure de Physique et Chimie Industrielles, 10 rue Vauquelin, F-75231 Paris Cedex 05,

France

\begin{abstract}
A series of structurally-related chromophores of different symmetry (quadrupolar, $C_{2 v}$, octupolar...) and shape (rod-like, propeller-shaped, Y-shaped, dendritic...) were investigated and compared for optimization of molecular two-photon absorption (TPA). Their design is based on the functionalization of linear or branched conjugated backbones with electronreleasing and/or electron-withdrawing peripheral groups. Their TPA spectra were determined by investigating their two-photon-excited fluorescence properties in the NIR region using pulsed excitation in the femtosecond regime. These studies provide evidence that the charge symmetry plays an important role in determining the TPA magnitude, the quadrupolar chromophore leading to the highest TPA cross-section. However, higher-order charge symmetries and branched-structures provide an interesting route for improvement of the nonlinear absorptivity/transparency range trade-off as well as for TPA spectral broadening in the NIR region.
\end{abstract}

Keywords: two-photon absorption (TPA); two-photon-excited fluorescence (TPEF); quadrupole; octupole; dendrimer

\section{Introduction}

" Present address: Boston University, BME Dept., 44 Cummington St., Boston, MA 02215 
Journal of Molecular Structure, Volume 704, Issues 1-3, 18 October 2004, Pages 17-24, http://dx.doi.org/10.1016/j.molstruc.2003.12.036

Molecular two-photon absorption (TPA) has attracted increasing interest over recent years owing to the many applications it offers. These include microfabrication [1], 3D optical data storage [2], photodynamic therapy [3], and two-photon laser scanning fluorescence imaging [4]. These applications call for the design of specifically engineered compounds displaying enhanced TPA cross-sections. In the case of two-photon-excited fluorescence (TPEF) microscopy, novel fluorophores combining high fluorescence quantum yield $(\phi)$ and TPA cross-section $\left(\sigma_{2}\right)$ orders of magnitude larger than endogenous chromophores in the redNIR range (700-1200 $\mathrm{nm}$ ) are desirable for non-damaging biological imaging. TPA also offers promising potentialities for optical power limitation [5]. Such a nonlinear process offers the possibility of maintaining high transparency in ambient light and achieving efficient and immediate protection against the high intensity delivered by pulsed lasers. Candidate molecules for optical power limitation should exhibit high solubility, high linear transmission at low intensities (i.e. low linear absorption) together with very large multiphoton absorptivities at the intensities delivered by high power pulsed lasers.

Until recently, optimization of molecular TPA has focused mainly on one-dimensional dipolar [6,7], or quadrupolar [7,8] structures. However, it has been realized lately that twodimensional [9], branched [10] and dendritic [11,12] structures could lead to highly effective multiphoton absorption. In this context, we have been interested in the elucidation of the role of dimensionality and charge-symmetry on molecular TPA. We have investigated a series of structurally-related chromophores of different symmetry (quadrupolar, $C_{2 v}$, octupolar...) and shape (rod-like, propeller-shaped, Y-shaped, dendritic...). Their design is based on the functionalization of either 1-D linear or 2-D branched conjugated backbones with electronreleasing or electron-withdrawing peripheral groups (Fig. 1a). The structures were built from biphenyl and its trigonal analogue 1,3,5-triphenylbenzene units as core/node moieties. The triphenylbenzene moiety acts as a trigonal node that maintains a large distance between the conjugated branches, thus preventing strong through-space electronic interactions. B3LYP abinitio calculations indicate that the branched chromophores derived from the trigonal core adopt a propeller-shaped structure, the conjugated branches being planar and twisted by about $38^{\circ}$ with respect to the core phenyl ring (Fig. 1b). Likewise, the quadrupolar chromophore $\mathbf{1}$ derived from the biphenyl core moiety displays two planar conjugated branches twisted by $34^{\circ}$ in the middle of the biphenyl moiety. Arylene-vinylene units were used as connecting spacers between the core/nodes and the peripheral groups to ensure effective electronic conjugation between end-groups and core/node moieties and allow multidimensional intramolecular charge transfer to take place within the chromophores. 
Journal of Molecular Structure, Volume 704, Issues 1-3, 18 October

2004, Pages 17-24, http://dx.doi.org/10.1016/j.molstruc.2003.12.036

The one- and two-photon absorption and fluorescence properties have been investigated and compared in order to evaluate the role of dimensionality and chargesymmetry on both their photophysical and TPA properties. In addition, HOMO-LUMO calculations have been carried out to provide additional information on the topology of the electronic charge redistribution occurring in those chromophores upon excitation.

\section{Experimental and computational details}

\subsection{Chromophores}

Molecules 1-4 (Fig. 1a) have been synthesized using the synthetic approach reported in ref. [12]. Their purity was checked by NMR, HRMS and elemental analysis prior to photophysical studies.

\subsection{Computational details}

Calculations and especially geometry optimization were conducted using the Gaussian 98 package [13] with the B3LYP [14] density functional and the 6-31G* basis set. For the sake of simplicity, calculations have been conducted on chromophores where the alkyl solubilizing chains have been replaced by methyl substituents. Illustrations have been obtained with MOLEKEL [15].

\subsection{Photophysical methods}

UV/VIS spectra were recorded on a Jasco V-570 spectrophotometer.

Steady-state and time resolved fluorescence measurements were performed at room temperature in diluted solutions $\left(\mathrm{ca} \cdot 10^{-6} \mathrm{M}\right)$ using an Edinburgh Instruments (FLS 920) spectrometer in photon-counting mode. Emission spectra were obtained, for each compound, at $\lambda_{\mathrm{ex}}=\lambda_{\max }(\mathrm{abs})$ with $\mathrm{A}_{\mathrm{ex}}=0.1$ to minimize internal absorption. Fluorescence quantum yields were measured on degassed samples at room temperature; fluorescein in $0.1 \mathrm{~N} \mathrm{NaOH}$ was used as a standard $\left(\phi=0.90\right.$ at $\left.\lambda_{\mathrm{ex}}=470 \mathrm{~nm}\right)$ and refractive index correction was performed [16]. The lifetimes values were obtained from the reconvolution fit analysis of the decay profiles with the F900 analysis software and the fitting results were judged by the reduced chi-square value. 
Journal of Molecular Structure, Volume 704, Issues 1-3, 18 October 2004, Pages 17-24, http://dx.doi.org/10.1016/j.molstruc.2003.12.036

Two-photon excitation cross-sections of chromophores 1-4 were determined by investigating their two-photon-excited fluorescence (TPEF) in solution. These measurements provide the TPEF action cross-section $\sigma_{2} \Phi$. The corresponding $\sigma_{2}$ values can be derived by determining the fluorescence quantum yield $\Phi$ from standard fluorescence measurements. TPEF measurements were conducted using a mode-locked Ti:sapphire laser operating between 740 and $1000 \mathrm{~nm}$ and delivering $80 \mathrm{fs}$ pulses at $80 \mathrm{MHz}$, following the experimental protocol described in detail by $\mathrm{Xu}$ and Webb [17]. The quadratic dependence of the fluorescence intensity on the excitation intensity was verified for every data point, indicating that the measurements were carried out in intensity regimes in which saturation or photodegradation did not occur. TPEF measurements were calibrated relative to the absolute TPEF action cross-section determined by $\mathrm{Xu}$ and Webb for fluorescein in water $(\mathrm{pH}=11)$ in the $690-1000 \mathrm{~nm}$ range $[17,18]$. For each data point, an additional control was performed by comparing with the TPEF action cross-section of rhodamine B in methanol [17,18]. The experimental uncertainty amounts to $\pm 10 \%$.

\section{Results and discussion}

\subsection{Photophysical properties}

The photophysical characteristics of chromophores 1-4 are summarized in Table 1. The chromophores show an intense absorption band in the near UV or visible region depending on their structure (Fig. 2a). Interestingly, we observe from Table 1 and Fig. 2a that increasing the branched character clearly results in improved transparency: a definite blueshift of the absorption band is observed in the series 1-4, paralleling the increasing number of branches in the chromophores. As a result branched chromophores 3-4 maintain very good transparency in the visible region. Such an effect can be of particular interest when applications such as optical power limiting are considered.

The fluorescence characteristics are dependent on dimensionality: 2-dimensional chromophores 2-4 show much lower fluorescence quantum yield than the 1-dimensional quadrupolar chromophore 1. In contrast, we observe that branched chromophores 2-4 exhibit similar fluorescence spectra (Fig.2b) and quantum yields (Table 1). We note that dendritic chromophores 3 (octupole: first generation) and 4 (second generation) exhibit similar fluorescence lifetimes, although chromophore 4 has an extinction coefficient about three 
Journal of Molecular Structure, Volume 704, Issues 1-3, 18 October 2004, Pages 17-24, http://dx.doi.org/10.1016/j.molstruc.2003.12.036

times larger than chromophore 3 . Since these chromophores display similar emission spectra and identical fluorescence quantum yields, one would expect a much lower radiative lifetime for chromophore 4 and hence lower fluorescence lifetime. This behavior suggests some excitation localization in dendritic chromophore 4.

All chromophores investigated in the present work show a common feature: they exhibit large Stokes shifts values as evidence of a significant nuclear reorganization taking place after excitation prior to emission. Such behavior can be related to the electronic redistribution occurring upon excitation. Indeed HOMO-LUMO calculations reveal that pronounced intramolecular charge transfer phenomena occur within the chromophores upon excitation: a pronounced charge density shift from the electron-releasing peripheral groups to the core is observed both in 1-D quadrupolar chromophore $\mathbf{1}$ and in 2-D octupolar chromophore 3 (Fig. 3a,b). In the case of Y-shaped chromophore 2, a directional intramolecular charge transfer from the donating end-groups towards the acceptor moiety is observed (Fig. 3c). Such a phenomenon is confirmed by the positive solvatochromism shown by chromophore 2: increasing the solvent polarity leads to a slight red-shift of its absorption band while a definite bathochromic shift of the emission band is observed (Fig. 4). This is consistent with the larger stabilization of the polar emitting excited-state with respect to the ground state by polar solvents. Interestingly, this dipolar type charge transfer phenomenon is observed though the donating and accepting moieties are not directly conjugated.

\subsection{Two-photon absorption}

The TPA spectra of chromophores 1-4 are shown in Fig. 5a. We note that for molecule 1, the TPA spectrum does not show a maximum in the $740-900 \mathrm{~nm}$ range, the TPA magnitude still increasing at $740 \mathrm{~nm}$. This indicates that the first TPA maximum is located at lower wavelength whereas the lowest energy one-photon absorption maximum is observed at 401 $\mathrm{nm}$. This shows that the lowest-energy two-photon allowed excited state is located at higher energy than the one-photon allowed excited state. Such behavior is in agreement with earlier theoretical and experimental observations reported for symmetrical quadrupolar chromophores $[8 \mathrm{a}, \mathrm{c}, \mathrm{d}, \mathrm{g}]$. In contrast, we observe that the TPA spectra of the branched chromophores $\mathbf{2}$ and $\mathbf{3}$ exhibit a local maximum close to twice the one-photon maximum absorption wavelength (i.e. $X$ and $Y$ GM at $770 \mathrm{~nm}=2 \times 385 \mathrm{~nm}$ ), indicating that for these molecules the lowest energy excited-state is both one-photon and two-photon allowed. For 
Journal of Molecular Structure, Volume 704, Issues 1-3, 18 October 2004, Pages 17-24, http://dx.doi.org/10.1016/j.molstruc.2003.12.036

dendritic molecule 4 , a plateau is observed in the wavelength range corresponding to twice the one-photon maximum absorption (i.e. at $750 \mathrm{~nm}=2 \times 375 \mathrm{~nm}$ ).

We note from Fig. 5a that the 1-D quadrupolar chromophore 1 shows higher TPA cross-section at $740 \mathrm{~nm}$ than the other branched structures. However, this observation is no longer valid when shifting to higher wavelengths: all 2-D branched structures become stronger two-photon absorbers than their 1-D quadrupolar analogue at $\lambda>780 \mathrm{~nm}$. Indeed, although the maximum TPA of the branched structures are lower than those of the quadrupolar chromophore (Table 1), the branched-structures definitely show broader and redshifted TPA band in the NIR region. As a result, the dendritic chromophore 4, which exhibits lower TPA cross-section than chromophore 1 at $740 \mathrm{~nm}$, also shows a three times larger TPA cross-section at $800 \mathrm{~nm}$. Hence increasing the branched character seems to be a promising route for improving the TPA-transparency trade-off, in particular in the context of broadband optical limitation.

It is particularly interesting to note that $\mathrm{Y}$-shaped chromophore $\mathbf{2}$ and three-branched octupolar chromophore $\mathbf{3}$ exhibit very similar TPA spectra, molecule $\mathbf{2}$ showing only slightly lower TPA cross-section while having a $20 \%$ lower molecular weight and showing similar transparency. This is particularly attractive in terms of optimizing the normalized TPA molecular efficiency $\sigma_{2} / \mathrm{MW}$ as shown in Fig. $5 \mathrm{~b}$. Along the same line of reasoning, comparison of the normalized TPA efficiency of octupolar chromophore 3 and of its secondgeneration dendritic analogue $\mathbf{4}$ shows that increased branching character, although leading to enhanced TPA in the NIR region (Fig. 5a) does not yield a net gain in normalized TPA efficiency (Fig. 5b). Interestingly, in the NIR region both the three-branched octupolar chromophore $\mathbf{3}$ and the Y-shaped chromophore $\mathbf{2}$ appear as the best candidates in terms of normalized TPA-transparency trade-off.

\section{Conclusion}

The present study provides evidence that modulation of the nonlinear absorptivity/transparency range trade-off can be achieved by playing on the charge symmetry and dimensionality in a series of structurally-related chromophores. Indeed, increasing the branched character clearly results in improved transparency, but also in a significant broadening of the TPA spectra in the NIR region. Hence although the 1-D quadrupolar chromophore show the highest TPA cross-sections close to the visible red, the branched chromophores offer a promising alternative for enhanced TPA in the NIR region while 
Journal of Molecular Structure, Volume 704, Issues 1-3, 18 October 2004, Pages 17-24, http://dx.doi.org/10.1016/j.molstruc.2003.12.036

maintaining suitable transparency in the visible region. Such behavior is particularly attractive in the context of the search for optimizing multiphoton absorbers for broadband optical power limitation $[8 g, 19]$.

\section{Acknowledgements}

MBD acknowledges financial support from CNRS (ATIP and NOI grants), and Rennes Métropole. L.P. received a fellowship from MENRT. Calculations were supported by the “Centre Informatique National de l'Enseignement Supérieur” (CINES-France).

\section{References}

[1] (a) S. Kawata, H.-B. Sun, T. Tanaka, K. Takada, Nature 412 (2001) 697-698. (b) W. Zhou, S.M. Kuebler, K.L. Braun, T. Yu, J.K. Cammack, C.K. Ober, J.W. Perry, S.R. Marder, Science 296 (2002) 1106-1109.

[2] (a) D.A. Parthenopoulos, P.M. Rentzepis, Science 245 (1989) 843-845. (b) J.H. Strickler, W.W. Webb, Opt. Lett. 16 (1991) 1780-1782.

[3] J.D. Bhawalkar, N.D. Kumar, C.F. Zhao, P.N. Prasad, J. Clin. Laser Med. Surg. 15 (1997) 201-204.

[4] (a) W. Denk, J.H. Strickler, W.W. Webb, Science 248 (1990) 73-76. (b) C. Xu, W. Zipfel, J.B. Shear, R.M. Williams, W.W. Webb, Proc. Natl. Acad. Sci. U. S. A. 93 (1996) 10763-10768. (c) D.R. Larson, W.R. Zipfel, R.M. Williams, S.W. Clark, M.P. Bruchez, F.W. Wise, W.W. Webb, Science 300 (2003) 1434-1437.

[5] (a) G.S. He, G.C. Xu, P.N. Prasad, B.A. Reinhardt, J.C. Bhatt, A.G. Dillard, Opt. Lett. 20 (1995) 435-437. (b) J.E. Ehrlich, X.L. Wu, I.-Y.S. Lee, Z.-Y. Hu, H. Röckel, S.R. Marder, J.W. Perry, Opt. Lett. 22 (1997) 1843-1845.

[6] (a) G.S. He, L. Yuan, N. Cheng, J.D. Bhawalkar, P.N. Prasad, L.L. Brott, S.J. Clarson, B.A. Reinhardt, J. Opt. Soc. Am. B 14 (1997) 1079-1087. (b) K.D. Belfield, D.J. Hagan, E.W. Van Stryland, K.J. Schafer, R.A. Negres, Org. Lett. 1 (1999) 1575-1578. (c) L. Antonov, K. Kamada, K. Ohta, F.S. Kamounah, Phys. Chem. Chem. Phys. 5 (2003) 1193-1197.

[7] (a) B.A. Reinhardt, L.L. Brott, S.J. Clarson, A.G. Dillard, J.C. Bhatt, R. Kannan, L. Yuan, G.S. He, P.N. Prasad, Chem. Mater. 10 (1998) 1863-1874. (b) O.-K. Kim, K.-S. Lee, H.Y. Woo, K.-S. Kim, G.S. He, S.H. Guang, J. Swiatkiewicz, P.N. Prasad, Chem. 
Journal of Molecular Structure, Volume 704, Issues 1-3, 18 October

2004, Pages 17-24, http://dx.doi.org/10.1016/j.molstruc.2003.12.036

Mater. 12 (2000) 284-286. (c) B. Strehmel, A.M. Sarker, H. Detert, ChemPhysChem 4 (2003) 249-259.

[8] (a) M. Albota, D. Beljonne, J.-L. Brédas, J.E. Ehrlich, J.-Y. Fu, A.A. Heikal, S.E. Hess, T. Kogej, M.D. Levin, S.R. Marder, D. McCord-Maughon, J.W. Perry, H. Röckel, M. Rumi, G. Subramaniam, W.W. Webb, X.-L. Wu, C. Xu, Science 281 (1998) 1653-1656. (b) L. Ventelon, M. Blanchard-Desce, L. Moreaux, J. Mertz, Chem. Commun. (1999) 2055-2056. (c) L. Ventelon, S. Charier, L. Moreaux, J. Mertz, M. Blanchard-Desce, Angew. Chem., Int. Ed. 40 (2001) 2098-2101. (d) O. Mongin, L. Porrès, L. Moreaux, J. Mertz, M. Blanchard-Desce, Org. Lett. 4 (2002) 719-722. (e) A. Abbotto, L. Beverina, R. Bozio, A. Facchetti, C. Ferrante, G.A. Pagani, D. Pedron, R. Signorini, Org. Lett. 9 (2002) 1495-1498. (f) Y. Iwase, K. Kamada, K. Ohta, K. Kondo, J. Mater. Chem. 13 (2003) 1575-1581. (g) M.G. Silly, L. Porrès, O. Mongin, P.-A. Chollet, M. Blanchard-Desce, Chem. Phys. Lett. 379 (2003) 74-80.

[9] (a) M. Drobizhev, A. Karotki, M. Kruk, N.Z. Mamardashvili, A. Rebane, Chem. Phys. Lett. 361 (2002) 504-512. (b) M. Drobizhev, A. Karotki, M. Kruk, A. Rebane, Chem. Phys. Lett. 355 (2002) 175-182. (c) O.S. Pyun, W. Yang, M.-Y. Jeong, S.H. Lee, K.M. Kang, S.-J. Jeon, B.R. Cho, Tetrahedron Lett. 44 (2003) 5179-5182.

[10] (a) M.P. Joshi, J. Swiakiewicz, F. Xu, P.N. Prasad, B.A. Reinhardt, R. Kannan, Opt. Lett. 23 (1998) 1742-1744. (b) S.-J. Chung, K.-S. Kim, T.-C. Lin, G.S. He, J. Swiatkiewicz, P.N. Prasad, J. Phys. Chem. B 103 (1999) 10741-10745. (c) G.S. He, J. Swiatkiewicz, Y. Jiang, P.N. Prasad, B.A. Reinhardt, L.-S. Tan, R. Kannan, J. Phys. Chem. A 104 (2000) 4805-4810. (d) S.-J. Chung, T.-C. Lin, K.-S. Kim, G.S. He, J. Swiatkiewicz, P.N. Prasad, G.A. Baker, F.V. Bright, Chem. Mater. 13 (2001) 40714076. (e) B.R. Cho, K.H. Son, H.L. Sang, Y.-S. Song, Y.-K. Lee, S.-J. Jeon, J.H. Choi, H. Lee, M. Cho, J. Am. Chem. Soc. 123 (2001) 10039-10045. (f) D. Beljonne, W. Wenseleers, E. Zojer, Z. Shuai, H. Vogel, S.J.K. Pond, J.W. Perry, S.R. Marder, J.L. Brédas, Adv. Funct. Mater. 12 (2002) 631-641. (g) J. Yoo, S.K. Yang, M.-Y. Jeong, H.C. Ahn, S.-J. Jeon, B.R. Cho, Org. Lett. 5 (2003) 645-648. (h) B.J. Zhang, S.-J. Jeon, Chem. Phys. Lett. 377 (2003) 210-216. (i) A. Abbotto, L. Beverina, R. Bozio, A. Facchetti, C. Ferrante, G.A. Pagani, D. Pedron, R. Signorini, Chem. Commun. (2003) 2144-2145. (j) O. Mongin, L. Porrès, C. Katan, T. Pons, J. Mertz, M. BlanchardDesce, Tetrahedron Lett. 44 (2003) 8121-8125. 
Journal of Molecular Structure, Volume 704, Issues 1-3, 18 October 2004, Pages 17-24, http://dx.doi.org/10.1016/j.molstruc.2003.12.036

[11] (a) A. Adronov, J.M.J. Fréchet, G.S. He, K.-S. Kim, S.-J. Chung, J. Swiatkiewicz, P.N. Prasad, Chem. Mater. 12 (2000) 2838-2841. (b) M. Drobizhev, A. Karotki, A. Rebane, C.W. Spangler, Opt. Lett. 26 (2001) 1081-1083. (c) M. Drobizhev, A. Karotki, Y. Dzenis, A. Rebane, Z. Suo, C.W. Spangler, J. Phys. Chem. B 107 (2003) 7540-7543. (d) C.W. Spangler, Z. Suo, M. Drobizhev, A. Karotki, A. Rebane, NATO Science Series, II: Math., Phys. and Chem. 100 (2003) 139-153.

[12] O. Mongin, J. Brunel, L. Porrès, M. Blanchard-Desce, Tetrahedron Lett. 44 (2003) 2813-2816.

[13] Gaussian 98, Revision A.11; Frisch, M. J.; Trucks, G. W.; Schlegel, H. B.; Scuseria, G. E.; Robb, M. A.; Cheeseman, J. R.; Zakrzewski, V. G.; Montgomery Jr., J. A.; Stratmann, R. E.; Burant, J. C.; Dapprich, S.; Millam, J. M.; Daniels, A. D.; Kudin, K. N.; Strain, M. C.; Farkas, O.; Tomasi, J.; Barone, V.; Cossi, M.; Cammi, R.; Mennucci, B.; Pomelli, C.; Adamo, C.; Clifford, S.; Ochterski, J.; Petersson, G. A.; Ayala, P. Y.; Cui, Q.; Morokuma, K.; Malick, D. K.; Rabuck, A. D.; Raghavachari, K.; Foresman, J. B.; Cioslowski, J.; Ortiz, J. V.; Stefanov, B. B.; Liu, G.; Liashenko, A.; Piskorz, P.; Komaromi, I.; Gomperts, R.; Martin, R. L.; Fox, D. J.; Keith, T.; AlLaham, M. A.; Peng, C. Y.; Nanayakkara, A.; Gonzalez, C.; Challacombe, M.; Gill, P. M. W.; Johnson, B.; Chen, W.; Wong, M. W.; Andres, J. L.; Head-Gordon, M.; S., R. E.; Pople, J. A.; Gaussian, Inc., Pittsburgh PA, 2001.

[14] A.D. Becke, J. Chem. Phys. 98 (1993) 5648-5652.

[15] MOLEKEL 4.0; Flükiger, P.; Lüthi, H. P.; Portmann, S.; Weber, J.; Swiss Center for Scientific Computing, Manno (Switzerland), 2000.

[16] J.N. Demas, G.A. Crosby, J. Phys. Chem. 75 (1971) 991-1024.

[17] C. Xu, W.W. Webb, J. Opt. Soc. Am. B 13 (1996) 481-491.

[18] M.A. Albota, C. Xu, W.W. Webb, Appl. Opt. 37 (1998) 7352-7356.

[19] Preliminary experiments provide evidence that branched chromophores 3 and $\mathbf{4}$ show promising optical limiting properties in the visible region in the nanosecond regime (D. Riehl, N. Izard, O. Mongin, M. Blanchard-Desce, to be published). 
Journal of Molecular Structure, Volume 704, Issues 1-3, 18 October 2004, Pages 17-24, http://dx.doi.org/10.1016/j.molstruc.2003.12.036

\section{Table 1}

One and two-photon photophysical data of molecules 1-4 in toluene

\begin{tabular}{cccccccccc}
\hline Compound & $\begin{array}{c}\lambda_{\text {abs }} \\
(\mathrm{nm})\end{array}$ & $\begin{array}{c}\varepsilon \\
\left(\mathrm{cm}^{-1} \cdot \mathrm{mol}^{-1} . \mathrm{L}\right)\end{array}$ & $\begin{array}{c}\lambda_{\text {cut-off }}{ }^{\mathrm{a}} \\
(\mathrm{nm})\end{array}$ & $\begin{array}{c}\lambda_{\mathrm{em}} \\
(\mathrm{nm})\end{array}$ & $\begin{array}{c}\text { Stokes Shift } \\
\left(\mathrm{cm}^{-1}\right)\end{array}$ & $\Phi^{\mathrm{c}}$ & $\begin{array}{c}\tau^{\mathrm{d}} \\
(\mathrm{ns})\end{array}$ & $\begin{array}{c}\sigma_{2}{ }^{\mathrm{e}} \\
(\mathrm{GM})\end{array}$ \\
\hline $\mathbf{1}$ & 401 & 83000 & 455 & 455 & 3000 & 0.81 & 0.82 & 905 \\
$\mathbf{2}$ & 385 & 91000 & 436 & 445 & 3500 & 0.37 & 0.79 & 405 \\
$\mathbf{3}$ & 384 & 131000 & 433 & 438 & 3200 & 0.36 & 0.63 & 510 \\
$\mathbf{4}$ & 375 & 360000 & 432 & 442 & 4000 & 0.37 & 0.60 & 810 \\
\hline
\end{tabular}

${ }^{\text {a }}$ Wavelength at which the transmittance is $95 \%$.

${ }^{\mathrm{b}}$ Stokes shift.

${ }^{\mathrm{c}}$ Fluorescence quantum yield determined relative to fluorescein in $0.1 \mathrm{~N} \mathrm{NaOH}$.

${ }^{\mathrm{d}}$ Experimental fluorescence lifetime.

${ }^{\mathrm{e}}$ TPA cross-section measured at $740 \mathrm{~nm} ; 1 \mathrm{GM}=10^{-50} \mathrm{~cm}^{4}$.s.photon ${ }^{-1}$. 
Journal of Molecular Structure, Volume 704, Issues 1-3, 18 October 2004, Pages 17-24, http://dx.doi.org/10.1016/j.molstruc.2003.12.036

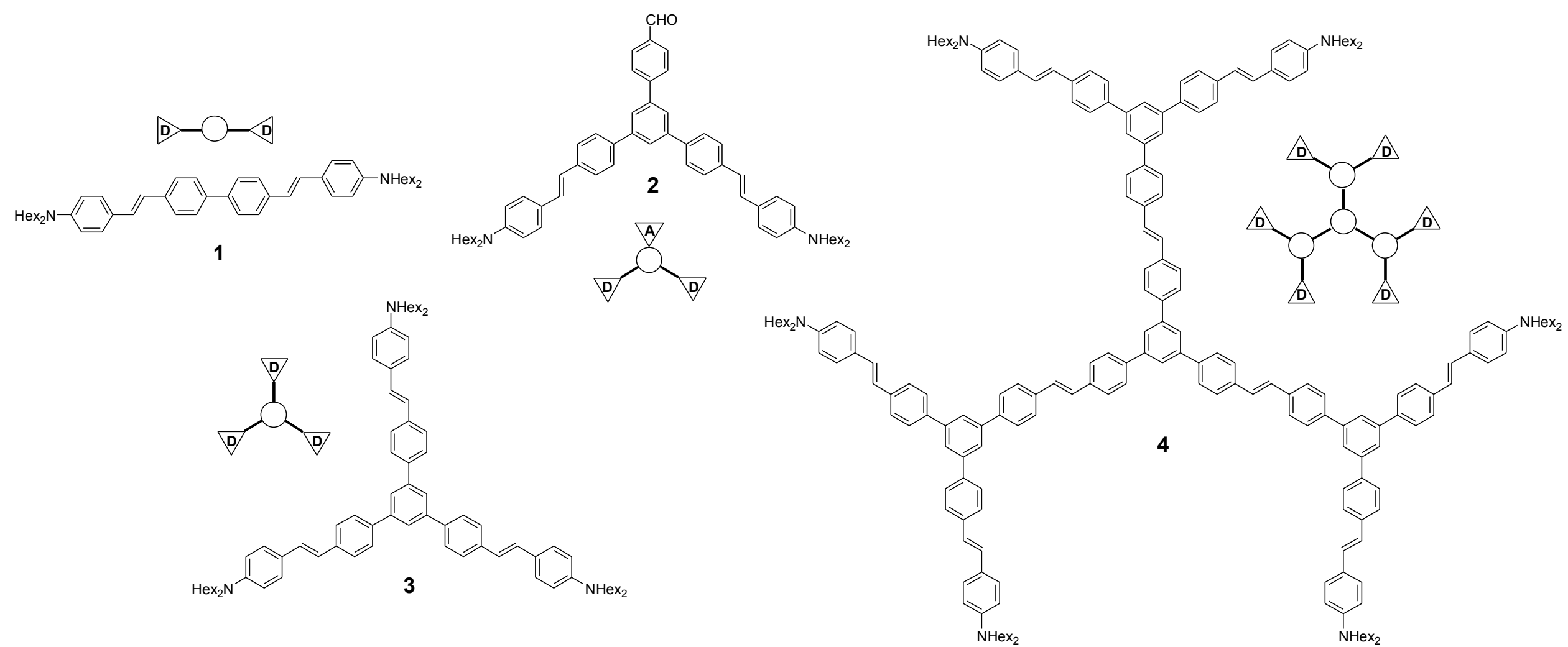

Fig. 1a. Series of structurally-related quadrupolar (1), Y-shaped (2), octupolar (3) and dendritic (4) chromophores. 
Journal of Molecular Structure, Volume 704, Issues 1-3, 18 October 2004, Pages 17-24, http://dx.doi.org/10.1016/j.molstruc.2003.12.036
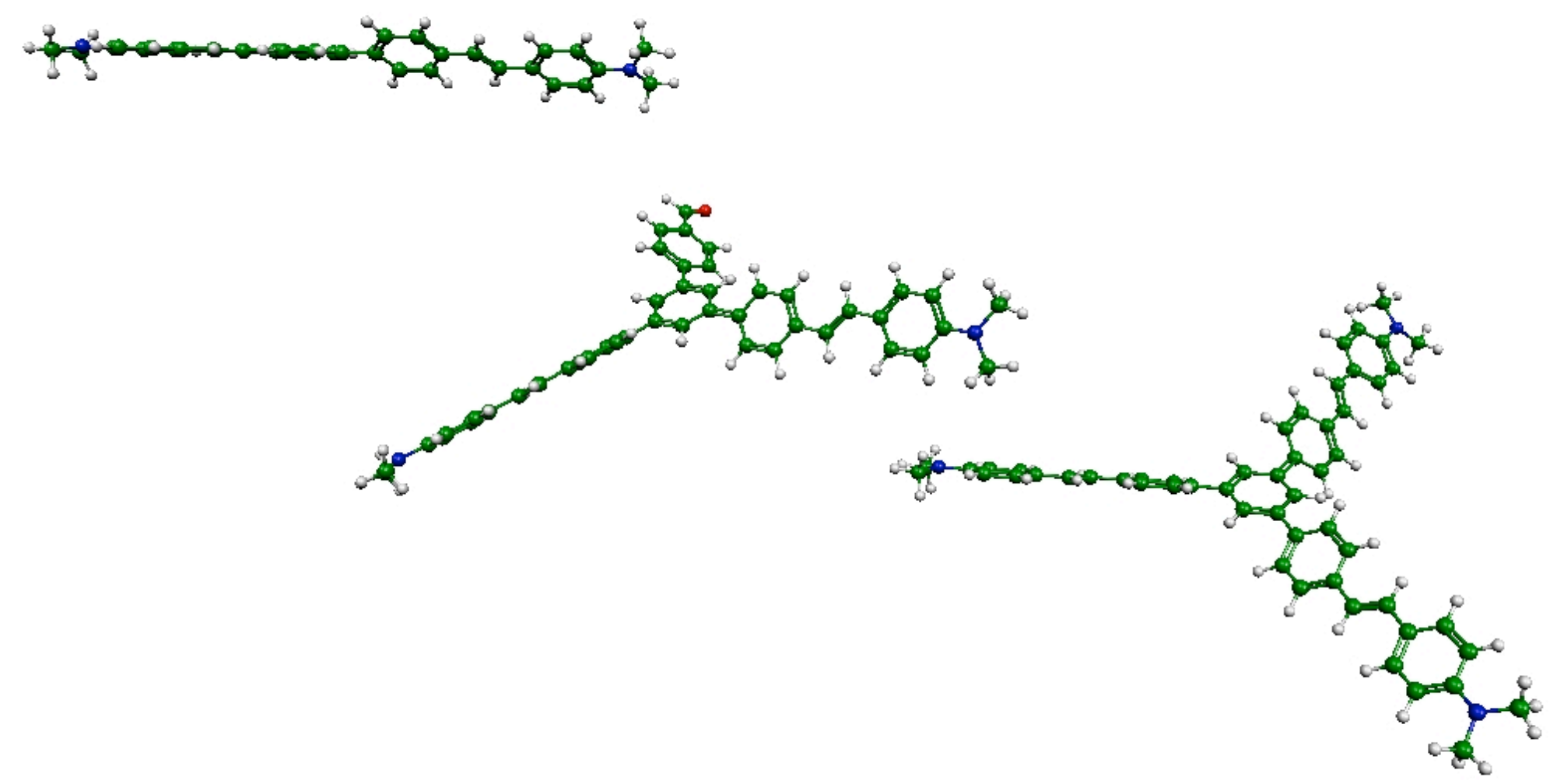

Fig. 1b. B3LYP optimized geometry of chromophores 1-3. 
Journal of Molecular Structure, Volume 704, Issues 1-3, 18 October 2004, Pages 17-24, http://dx.doi.org/10.1016/j.molstruc.2003.12.036
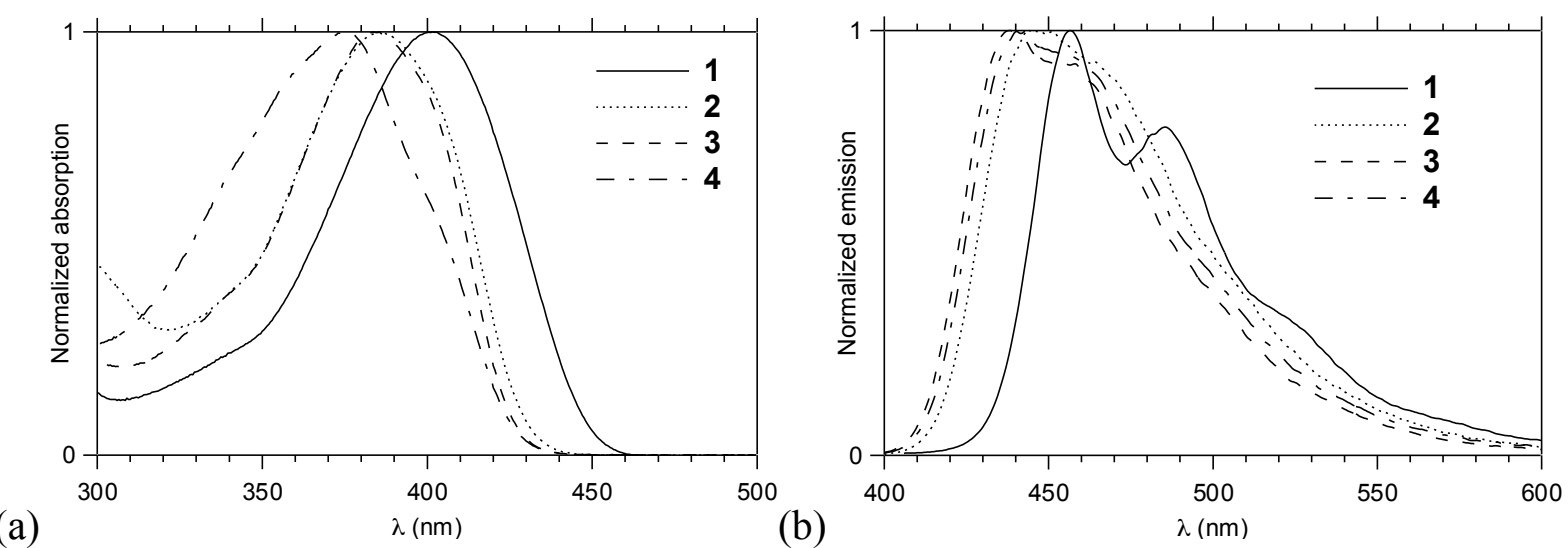

Fig. 2. Normalized absorption (a) and fluorescence emission spectra (b) of chromophores 1-4 in toluene. 
Journal of Molecular Structure, Volume 704, Issues 1-3, 18 October 2004, Pages 17-24, http://dx.doi.org/10.1016/j.molstruc.2003.12.036

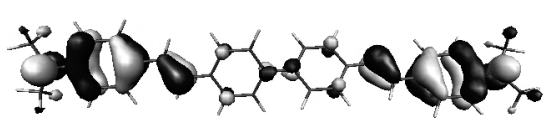

(a)

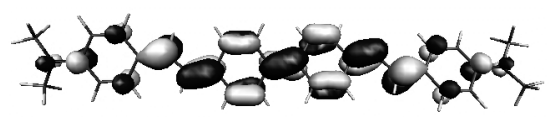

(c)

Fig. 3a. Frontier orbitals of chromophore 1: HOMO-1 (a), HOMO (b), LUMO (c), and $\mathrm{LUMO}+1$ (d).

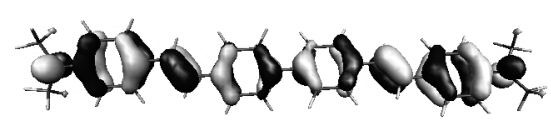

(b)

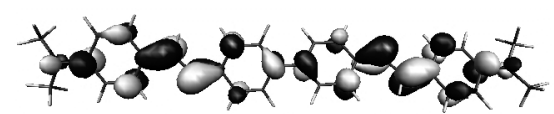

(d) 
(a)

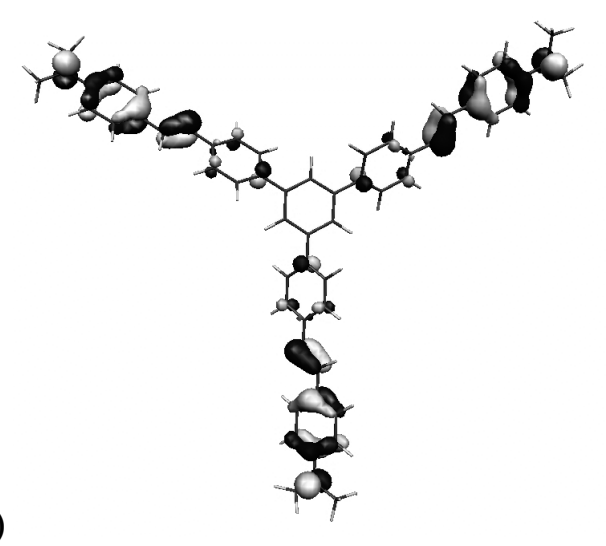

(b)

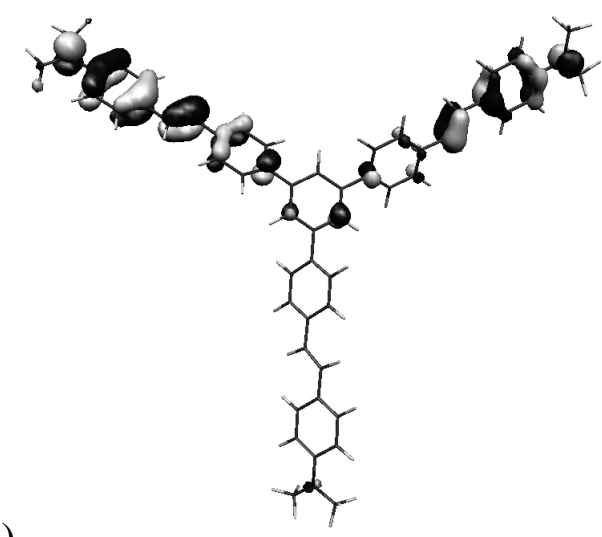

(c)

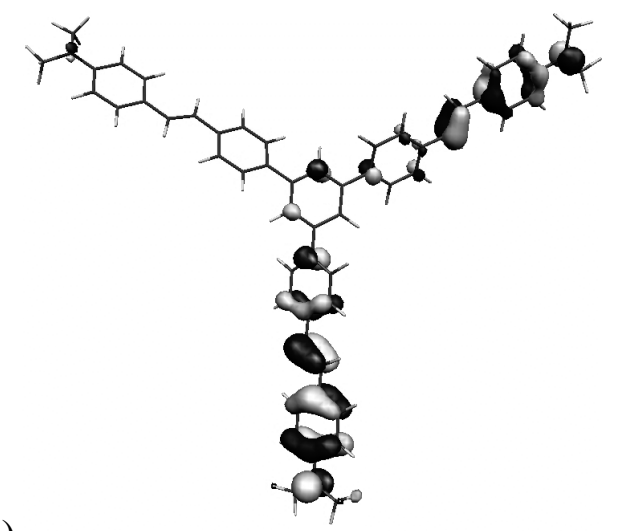

c)

(d)

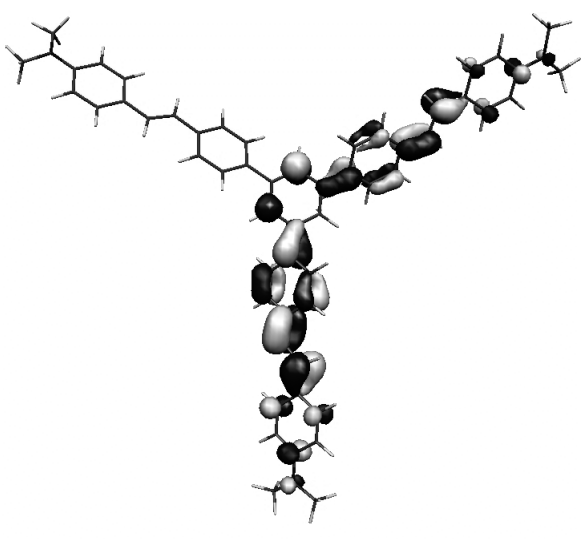

(e)
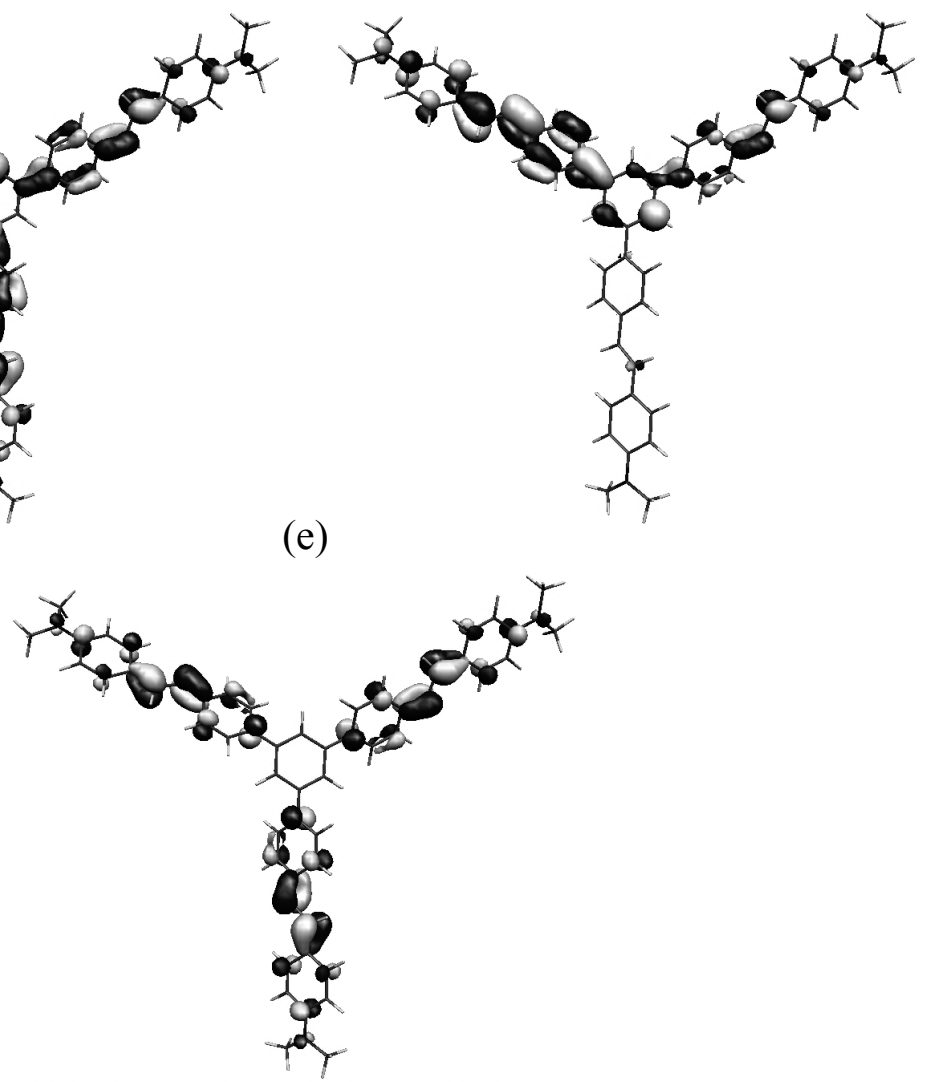

(f)

Fig. 3b. Frontier orbitals of chromophore 3: HOMO-2 (top: a), degenerated HOMO-1 and HOMO (b, c), degenerated LUMO and LUMO+1 (d, e) and LUMO+2 (down: f). 


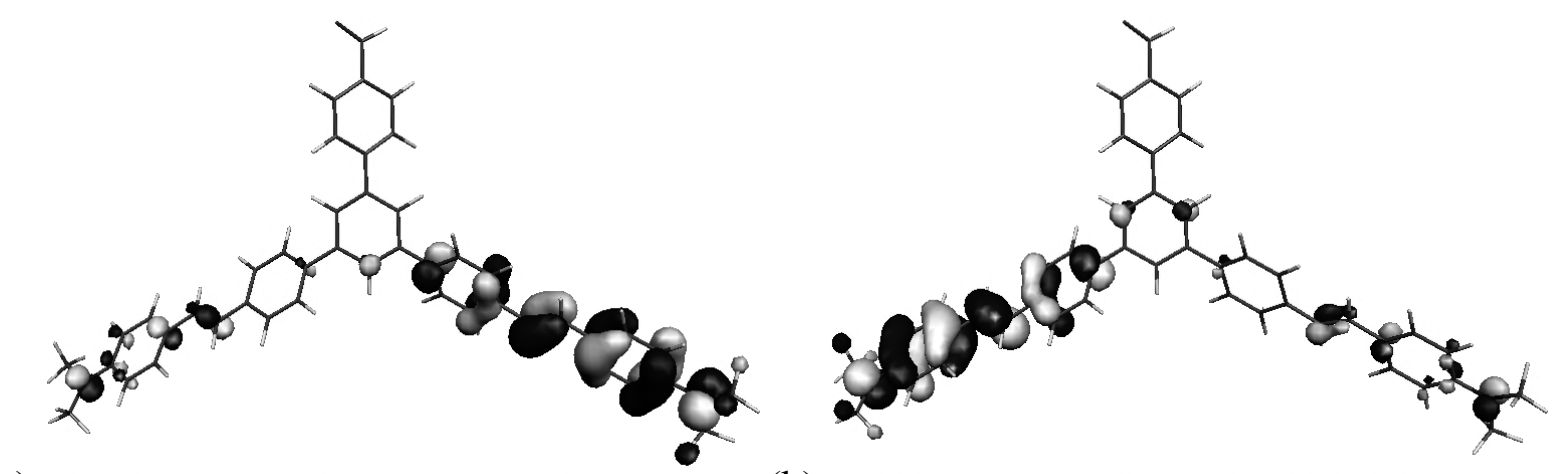

(a)

(b)
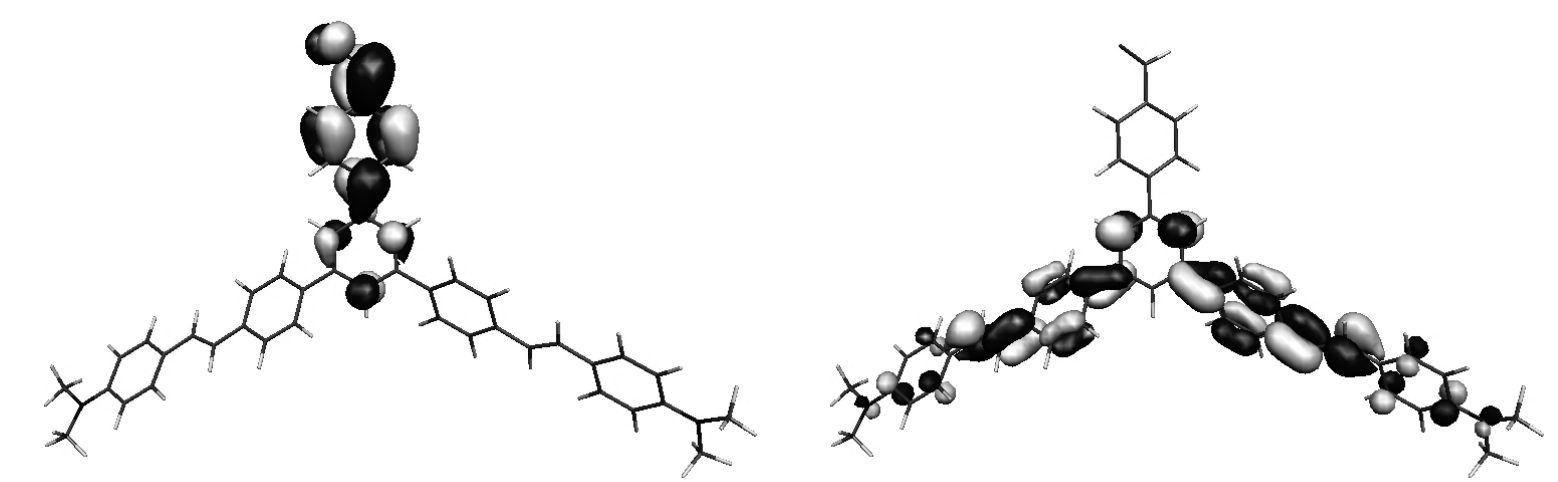

(c)

(d)

Fig. 3c. Frontier orbitals of chromophore 2: degenerated HOMO-1 and HOMO (top: a, b), LUMO (down left: c) and LUMO+1 (down right: d). 
Journal of Molecular Structure, Volume 704, Issues 1-3, 18 October 2004, Pages 17-24, http://dx.doi.org/10.1016/j.molstruc.2003.12.036

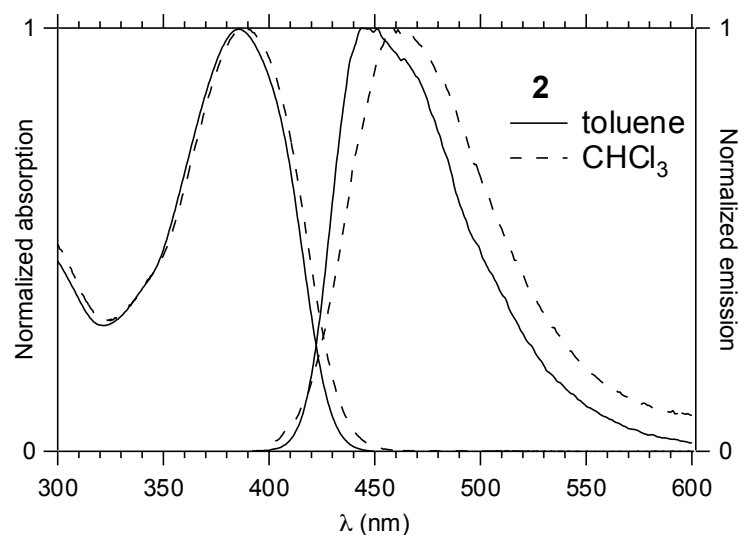

Fig. 4. Solvatochromic behavior of chromophore 2.

(a)

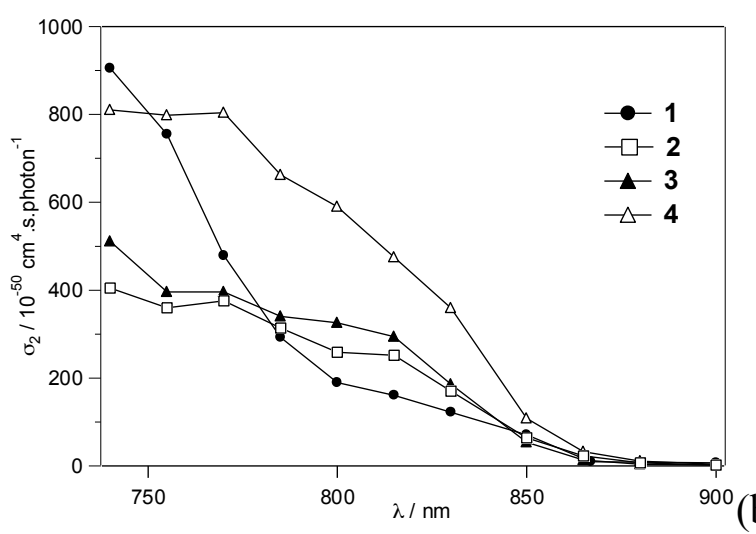

(b)

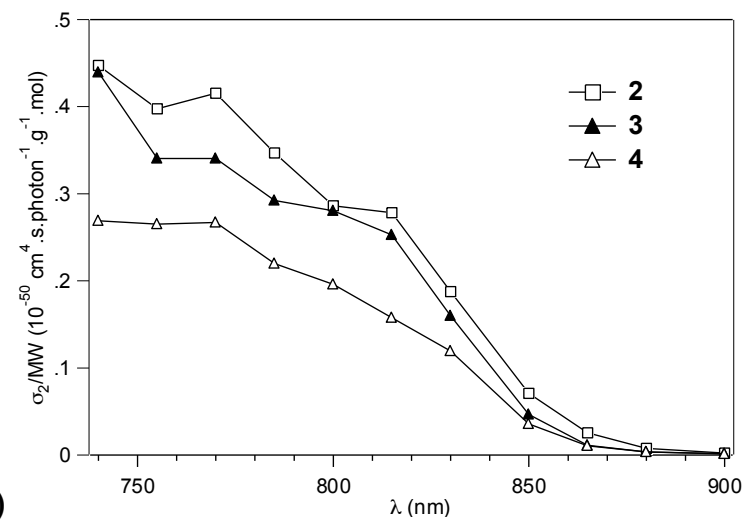

Fig. 5. Two-photon excitation spectra of molecules 1-4 in toluene. 